\title{
Savaş Alanı Turizmi: Bir Literatür Taraması
}

\author{
Yrd. Doç. Dr. Ozan ÇATIR \\ Uşak Üniversitesi, Ulubey Meslek Yüksekokulu. \\ e-posta: ozan.catir@usak.edu.tr
}

Öz

$\mathrm{Bu}$ çalışmanın amacı, savaş alanı turizmiyle ilgili ulusal ve uluslararası alandaki 1997-2015 yılları arasında yayınlanan makalelerin incelenmesidir. Savaş alanı turizmiyle ilgili yazın taraması Uşak Üniversitesi ekütüphanesinin veri tabanından elde edilmiştir. Ulaşılan makalelerden 1997-2015 yılları arasındaki 51 çalışma incelemeye alınmıştır. Çalışmanın sonucunda, en fazla turistlerin savaş alanlarıyla ilgili memnuniyet, motivasyon ve ziyaret nedenlerini belirlemeye yönelik çalışmaların yapıldı̆̆ı tespit edilmiştir.

Anahtar Kelimeler: Hüzün Turizmi, Savaş Alanı Turizmi, Yazın İncelemesi.

Türk Turizm Araştırmaları Dergisi Cilt. 1, Sayı.1, 2017 ss.21-31.

DOI: 10.26677/tutad.2017.1

\section{Önerilen Atıf:}

Çatır, O. (2017). Savaş Alanı Turizmi: Bir Literatür Taraması, Türk Turizm Araştırmaları Dergisi, Cilt.1, Sayı.1, ss.21-31. 


\title{
Battlefield Tourism: A Literature Review
}

\author{
Assistant Prof. Dr. Ozan ÇATIR \\ Uşak University, Ulubey Vocational School. \\ e-mail: ozan.catir@usak.edu.tr
}

\begin{abstract}
The aim of this study is to examine the articles published between 1997 and 2015 on national and international issues related to battlefield tourism. The literature survey on battlefield tourism was obtained from the database of the Uşak University e-library. 51 articles from 1997 to 2015 were taken into consideration. As a result of the study, it was determined that the tourists related to the battlefields were made to determine the reasons of satisfaction, motivation and visit.

Keywords: Dark Tourism, Battlefield Tourism, Literature Review.
\end{abstract}

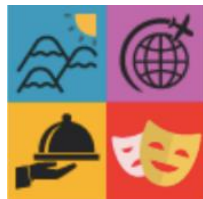

Journal of Turkish Tourism Research Vol. 1, Issue.1, 2017

pp.21-31.

\section{Suggested Ctitation:}

Çatır, O. (2017). Battlefield Tourism: A Literature Review, Journal of Turkish Tourism Research, Vol.1, Issue.1, pp.21-31. 


\section{Gíriş}

İnsanları turizm hareketlerine yönlendiren birçok sebep vardır. Çoğunlukla insanlar tatil amaçlı seyahatler gerçekleştirmekle birlikte; sağlık, spor, inanç vb. amaçlarla da seyahat etmektedirler. Çalışmanın konusunu oluşturan savaş alanları da insanların merak ettiği unsurlardan biridir. Savaşlar toplumları maddi ve manevi şekilde etkileyen olaylardır. Savaş sonrası hem fiziksel değişimler, hem de toplumsal değişimler meydana gelmektedir. İnsanlar, savaş alanlarını ziyaret ederek, savaşın nasıl gerçekleştiğini, savaşın acılarını, anıtları ve mezarları görmek istemektedirler. Bu amaçla gerçekleştirilen turizm çeşidine savaş alanı turizmi denilmektedir.

Türkiye'de tarih boyunca birçok savaş gerçekleşmiştir. İnsanlar, savaşların gerçekleştiği alanları, şehitlikleri ve anıtları ziyaret etmek istemektedirler. Bu bakımdan savaş alanlarının turizm amaçlı kullanılması mümkün olmaktadır. Gelibolu Tarihi Milli Parkı, Başkomutan Tarihi Milli Parkı, Sakarya Meydan Muharebesi Tarihi Milli Parkı, Sarıkamış Allahuekber Dağları Milli Parkı vb. savaş alanları turizmi için uygun destinasyon bölgelerine örnek olabilir. Yapılan araştırma kapsamında savaş alanları turizmini gerçekleştirecek olan grubun potansiyel turist grubunda yer alması savaş alanı turizmiyle ilgili literatür bilginin gerekliliğini de ortaya çıkarmaktadır. Savaş alanı turizmiyle ilgili yeterli bilgi akademik çalışmalardan faydalanarak sağlanabilir.

Çalışmanın amacı 1997-2015 yılları arasında savaş alanı turizmiyle ilgili yapılan makalelerin derlenerek, yazın incelemesinin yapılmasıdır. Savaş alanı turizmiyle ilgili veri tabanları taranmış, ulusal ve uluslararası toplam 51 çalışma incelemeye alınmıştır. Çalışmanın sınırlılıkları aşağıda maddeler halinde açılanmıştır:

- Araştırmanın daha hizlı ve maliyetlerin minimize edilmesi esasına dayanarak; sadece konu ile ilgili yapılmış ve rastlanan makaleler incelemeye alınması (kitap, tez, tanıtım broşürü vb. yayınlar dikkate alınmamıştır),

- Savaş alanı turizmiyle ilgili makalelere ulaşmak için sadece Uşak Üniversitesi ekütüphanesi (veri tabanı) kullanılması,

- Savaş alanı turizmiyle ilgili makalelere ulaşmak için anahtar kelime olarak sadece "battlefield tourism" kelimesinin kullanılması,

- Bu anahtar kelime ile tarama yapıldığında 64 makaleye ulaşılmış ve 51'i incelenmeye uygun görülmesi, incelemeye uygun görülmeyen 13 makalede ise; gezi notu, tanıtım, açılama vb. şeklinde konuların yer alması ve "Battlefield tourism" anahtar kelimesi ile yapılan araştırma sonucunda 1997-2015 yılları arasındaki makalelere ulaşılmasıdır (ilk olarak 1997 yılındaki yapılmış ve ulaşılan çalışma).

Çalışmada savaş alanı turizmi kavramı açıklanmış, savaş alanı turizmiyle ilgili yayınların konuları tablo halinde sunulmuş ve elde edilen bulgular ışığında uygulamacılara (yerel yönetim ve özel işletme yöneticileri) ve araştırmacılara öneriler getirilmiştir.

\section{HÜZÜN VE SAVAŞ ALANI TURIZMI}

Yapılan yazın taramasında savaş alanı turizminin daha çok hüzün turizmi kavramının altında incelendiği görülmüştür. Hüzün turizmi ilk kez 1990'lı yıllarda Lennon ve Foley (1996) tarafından geliştirilen bir kavramdır (Alaeddinoğlu ve Aliağaoğlu, 2007: 217). Foley ve Lennon'a göre (1996:198) hüzün turizmi, bir fenomen olarak ziyaretçilerin gerçek veya metalaşmış ölüm ve felaket alanlarının ziyaretlerini kapsar. Seaton (1999:131), hüzün turizmini "ölümle sembolik veya gerçek olarak karşılaşma arzusuyla seyahat etme" şeklinde tanımlamıştır. Hüzün turizminin, black spot (kara nokta), morbid (korkunç) ve battlefield (askeri alan) turizmi çok 
farklı şekilde isimlendirildiği görülmüştür. Miles hüzün turizminin; idamları, suikastları, mezarlıkları, toplu mezarları ve anıtları, hapishaneleri, toplama kamplarını ve savaş bölgelerini ziyaretleri içerdiğini ifade etmiştir (Miles, 2014:135).

Seaton (1999:131) çalışmasında, hüzün turizmi beş gruba ayırmıştır. Birinci grup idam cezasını izlemek için yapılan seyahatlerdir. İkinci grup bireysel veya toplu ölümlerin gerçekleştikleri yerleri görmek için yapılan seyahatlerdir. Bu seyahatler çok yaygın olarak görülmektedir. Vahşet alanlarına, afet alanlarına, ünlü kişilerin ölüm alanlarına ve savaş alanlarına yapılan seyahatler bu gruba örnek olarak verilebilir. Üçüncü grup, hapishaneler, mezarlıklar, anıtlar, türbeler ve savaş alanları gibi ölümü akla getiren alanlara yapılan seyahatlerdir. Dördüncü grup, müze gibi özellikle ölümü ve savaşı hatırlatan sembolleri ve hatıralara yapılan seyahatlerdir. Ölülere ait hatıra eşyalar, silahlar, giysileri görmek için yapılan seyahatler örnek olarak verilebilir. Beşinci grupta dini amaçlı acı çeken birinin yaşadığı alanı ziyaret şeklinde olabilir.

Brian, Poria ve Oren (2011) hüzün turizminin kapsadığı savaş alanı turizmin üç farklı bakış açısıyla incelenmiştir. İlk olarak ölümle ve acıyla ilgili ürkütücü görünen yerlere yapılan seyahatler. İkinci olarak, seyahat motivasyonlarına neden olan talep akışı incelemeleri (talebin ölümle ilgili olaylara olması gerekmektedir), üçüncü olarak da bireyin deneyimleriyle bölgenin özelliklerini bir araya getiren arz-talep dengesi açısından savaş alanı turizmi incelenmiştir.

\section{SAVAŞ ALANI TURIZMINE İLIŞKINN YAZIN TARAMASI}

Konuyla ilgili yapılan araştırmalar gelecekte yapılacak yeni çalışmalara rehber olabilecek niteliktedir. Yapılan araştırmaya ilişkin elde edilen önemli sonuçlar Tablo 1'de sıralanmış ve her biri aşağıda özetlenmiş̧ir.

Tablo 1. Savaş Alanı Turizmiyle İlgili Çalışmaların Konuları

\begin{tabular}{ccc}
\hline Yazar/Yazarlar & Konu & Yll \\
\hline Floyd, Jang ve Noe & Çevre & 1997 \\
Seaton & Savaş Alanı (Hüzün) Turizmi Uygulamaları & 1999 \\
Blom & Savaş Alanı (Hüzün) Turizmi Uygulamaları & 2000 \\
Hanink ve Stutts & Talep Analizi & 2002 \\
Gatewood ve Cameron & Memnuniyet, Motivasyon ve Ziyaret Etme Nedeni & 2004 \\
Holguin & Tanıtım, Pazarlama ve Paket Tur Oluşturma & 2005 \\
Adams & Diğer (Savaş Alanlarının Kiyaslanması) & 2005 \\
Cooper & Tanıtım, Pazarlama ve Paket Tur Oluşturma & 2006 \\
Knox & Mabetleştirme & 2006 \\
Gibson & Diğer (Seri Katiller) & 2006 \\
Iles & Tanıtım, Pazarlama ve Paket Tur Oluşturma & 2006 \\
Gentry & Savaş Alanı (Hüzün) Turizmi Uygulamaları & 2007 \\
Lunn & Savaş Alanı (Hüzün) Turizmi Uygulamaları & 2007 \\
Hughes & Mabetleştirme & 2007 \\
West & Memnuniyet, Motivasyon ve Ziyaret Etme Nedeni & 2008 \\
Iles & Tanıtım, Pazarlama ve Paket Tur Oluşturma & 2008 \\
Robb & Tanıtım, Pazarlama ve Paket Tur Oluşturma & 2008 \\
Winter & Memnuniyet, Motivasyon ve Ziyaret Etme Nedeni & 2009 \\
Levitt & Tanitım, Pazarlama ve Paket Tur Oluşturma & 2009 \\
Alaeddinoğlu ve Aliağaoğlu & Diğer (Film ve hüzün turizmi ilişkisi) & 2010 \\
Zhang & Memnuniyet, Motivasyon ve Ziyaret Etme Nedeni & 2010 \\
\hline Hall, Basarin ve Binney & Tanıtım, Pazarlama ve Paket Tur Oluşturma & 2010 \\
\hline & Savaş Alanı (Hüzün) Turizmi Uygulamaları & 2010 \\
\hline
\end{tabular}


Türk Turizm Araştırmaları Dergisi

\begin{tabular}{|c|c|c|}
\hline Yazar/Yazarlar & Konu & Yil \\
\hline Dunkley, Morgan ve Westwood & Memnuniyet, Motivasyon ve Ziyaret Etme Nedeni & 2011 \\
\hline Le ve Pearce & Memnuniyet, Motivasyon ve Ziyaret Etme Nedeni & 2011 \\
\hline Hyde ve Harman & Memnuniyet, Motivasyon ve Ziyaret Etme Nedeni & 2011 \\
\hline Clarke ve Eastgate & Memnuniyet, Motivasyon ve Ziyaret Etme Nedeni & 2011 \\
\hline Daugbjerg & Savaş Alanlarında Barışın Önemi & 2011 \\
\hline Walby ve Piche & Savaş Alanı (Hüzün) Turizmi Uygulamaları & 2011 \\
\hline Winter & Memnuniyet, Motivasyon ve Ziyaret Etme Nedeni & $2011 \mathrm{a}$ \\
\hline Winter & Memnuniyet, Motivasyon ve Ziyaret Etme Nedeni & $2011 b$ \\
\hline Yeşildağ ve Atay & Memnuniyet, Motivasyon ve Ziyaret Etme Nedeni & 2011 \\
\hline Kılıç, Kurnaz ve Sop & Tanıtım, Pazarlama ve Paket Tur Oluşturma & 2011 \\
\hline Kılıç ve Akyurt & Tanitım, Pazarlama ve Paket Tur Oluşturma & 2011 \\
\hline Liu & Çevre, Yenilenebilir Enerji Kaynakları & 2012 \\
\hline Ağaoğlu & Memnuniyet, Motivasyon ve Ziyaret Etme Nedeni & 2012 \\
\hline Engström ve Boluk & Savaşa Alanı Turizminin Yerel Halka Etkisi & 2012 \\
\hline Rofe & Savaş Alanı (Hüzün) Turizmi Uygulamaları & 2012 \\
\hline Herborn ve Hutchinson & Savaş Alanlarında Barışın Önemi & 2012 \\
\hline McKay & Savaş Alanlarında Barışın Önemi & 2013 \\
\hline Coats ve Ferguson & Savaşa Alanı Turizminin Yerel Halka Etkisi & 2013 \\
\hline Kurnaz, Çeken ve Kılıç & Memnuniyet, Motivasyon ve Ziyaret Etme Nedeni & 2013 \\
\hline Pieris & Savaş Alanı (Hüzün) Turizmi Uygulamaları & 2014 \\
\hline Melstrom & Talep Analizi & 2014 \\
\hline Ravi & Savaş Alanı (Hüzün) Turizmi Uygulamaları & 2014 \\
\hline Alexandra, Alexandru ve Larisa & Diğer (Film ve hüzün turizmi ilişkisi) & 2014 \\
\hline Volcic, Erjavec ve Peak & Tanıtım, Pazarlama ve Paket Tur Oluşturma & 2014 \\
\hline $\begin{array}{l}\text { Clarke, Dutton ve } \\
\text { Jonhston }\end{array}$ & Savaş Alanı (Hüzün) Turizmi Uygulamaları & 2014 \\
\hline Miles & Savaş Alanı (Hüzün) Turizmi Uygulamaları & 2014 \\
\hline MacCarthy ve Wilson & Tanıtım, Pazarlama ve Paket Tur Oluşturma & 2015 \\
\hline Yırık ve Seyitoğlu & Mabetleştirme & 2015 \\
\hline
\end{tabular}

Özetlenen bu çalışmalar konu, uygulama yeri ve yıla göre sınıflandırılarak, aşağıda açıklanmıştır. Çalışmaların konularına göre dağılımı Şekil 1'de sunulmuştur.

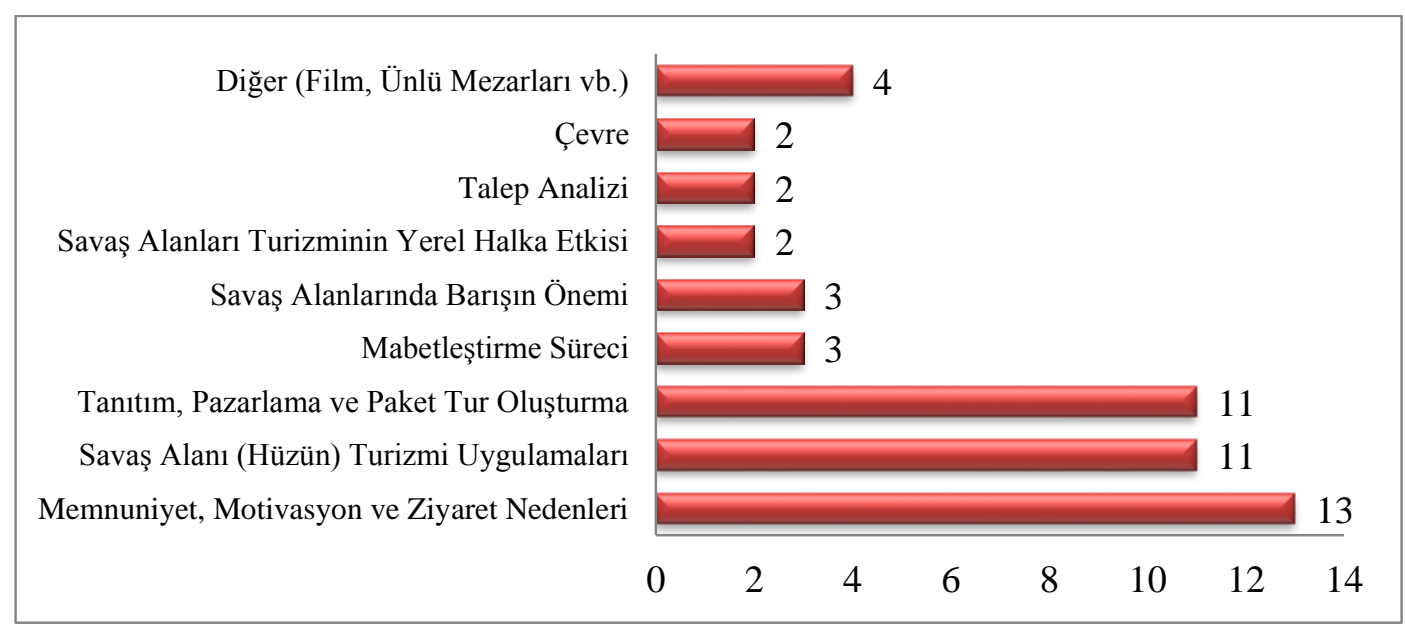

Şekil 1. Konularına Göre Çalışmaların Dağılımı

Şekil 1 incelendiğinde, en fazla çalışmanın memnuniyet, motivasyon ve ziyaret nedenleriyle ilgili yapıldığı görülmektedir. Savaş alanı (hüzün) turizmi uygulamaları ve tanıtım, pazarlama ve paket tur oluşturma ile ilgili çalışmaların da yoğun olarak çalışıldığı ifade edilebilir. Bu 


\section{Ozan ÇATIR}

konular dışında çalışılan diğer konuların hem ulusal hem de uluslararası düzeyde incelenmesi gerekmektedir. Çalışmanın yapıldığı ülkeye göre çalışmaların dağılımı Şekil 2'de verilmiştir.

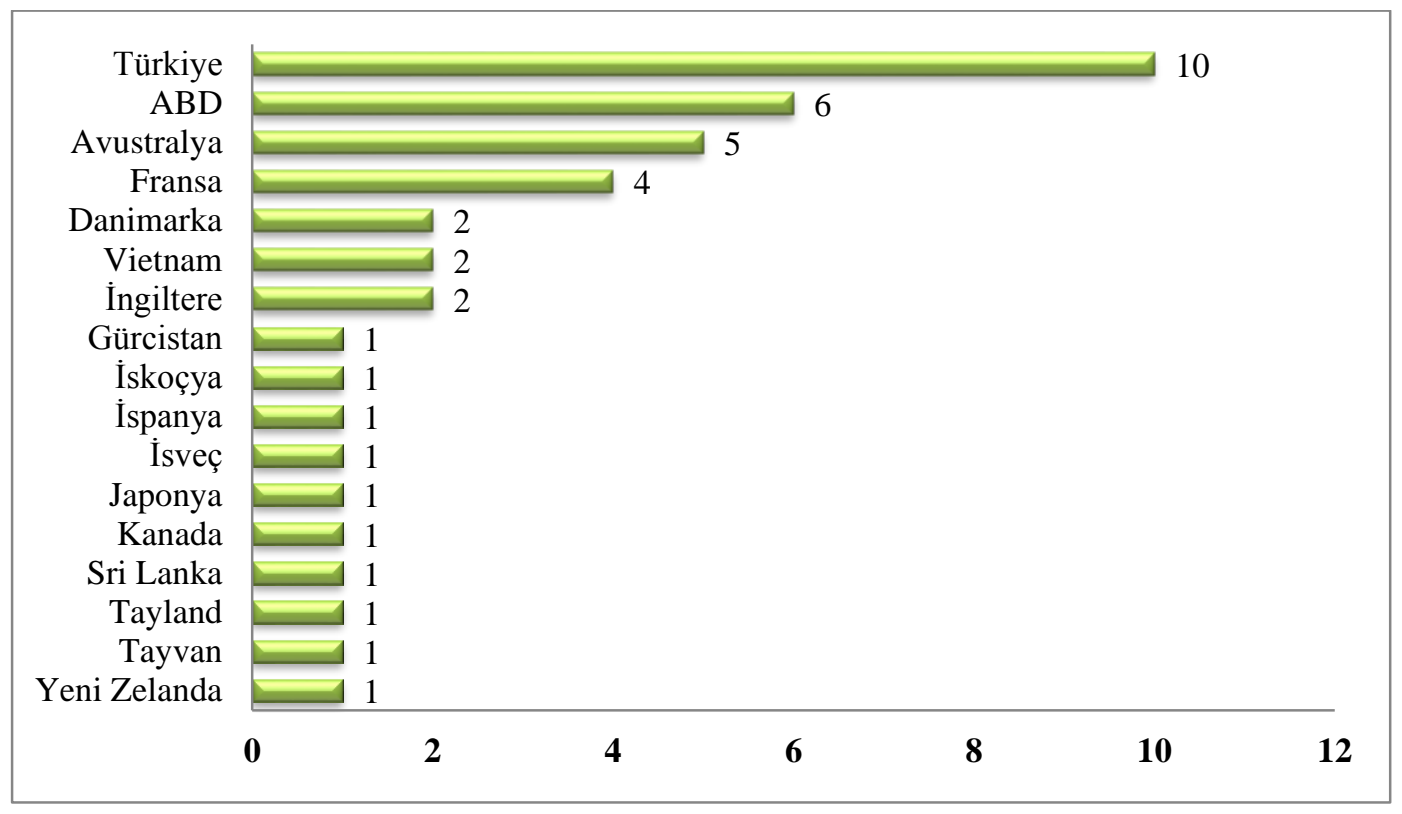

Şekil 2. Çalışmanın Yapıldığı Ülkeye Göre Çalışmaların Dağılımı

Şekil 2 incelendiğinde en fazla çalışmanın Türkiye'de yapıldığı, daha sonra Amerika ve Avustralya ve Fransa'da yapıldığı görülmektedir. Türkiye'de yapılan çalışmaların çoğunluğu Çanakkale Gelibolu'ya gelen Avustralyalılar üzerinde gerçekleştirilmiştir.

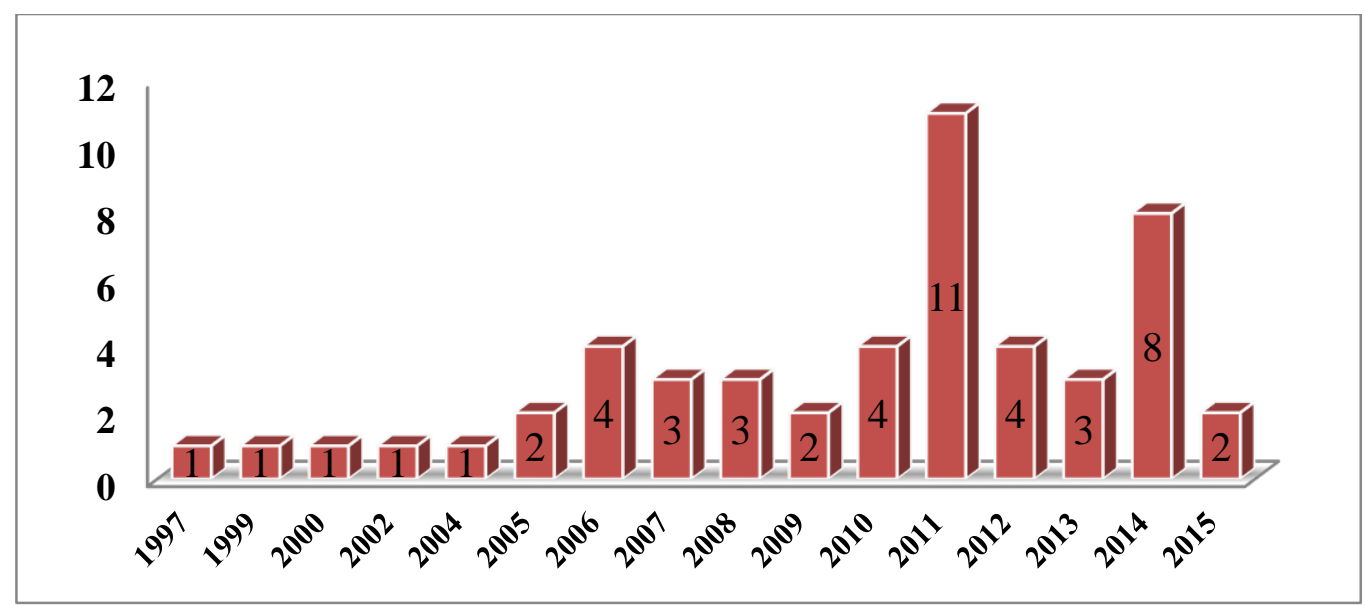

Şekil 3 Yapılmış Çalışmaların Yıllara Göre Dağılımı

Şekil 3’de görüldüğü üzere, savaş alanı turizmiyle ilgili yayınların en fazla 2011 ve 2014 yıllarında yapılmıştır. Diğer yıllarda ise, bu konuda çalışmaların az sayıda olduğu görülmektedir. Şekil 4'te incelenen çalışmaların yöntemlerine göre dağılımları verilmiştir. 
Türk Turizm Araştırmaları Dergisi

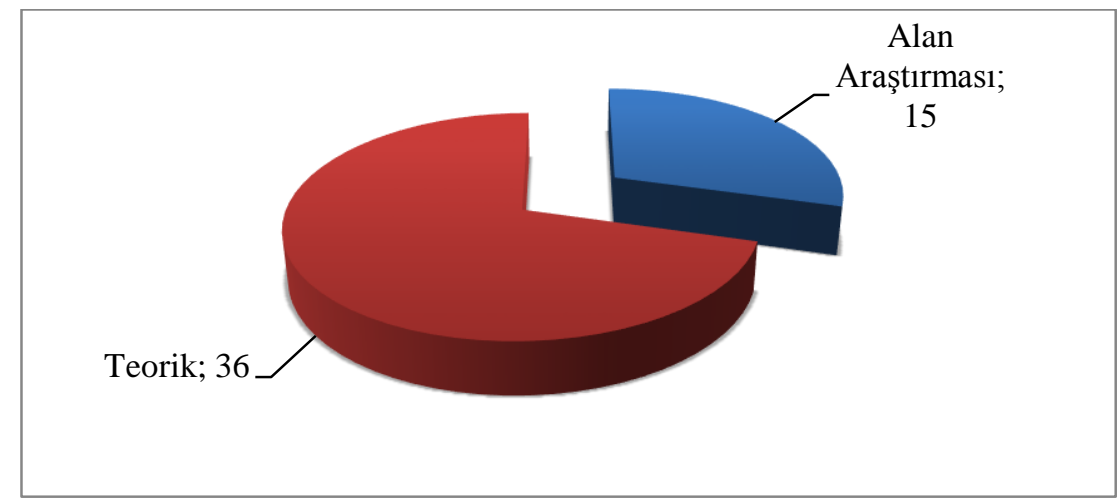

Şekil 4 Yapılmış Çalışmaların Yöntemlerine Göre Dağılımı

Şekil 4 incelendiğinde, yazın incelemesinin yapıldı̆̆ı teorik çalışmaların fazla olduğu görülmektedir. Uygulamaya yönelik yapılan çalışmaların sayısı ise $15^{\prime}$ tir. Uygulamaya yönelik yapılmış olan çalışmaların örneklem büyüklüklerine göre dağılımı ise Şekil 5'te gösterilmektedir.

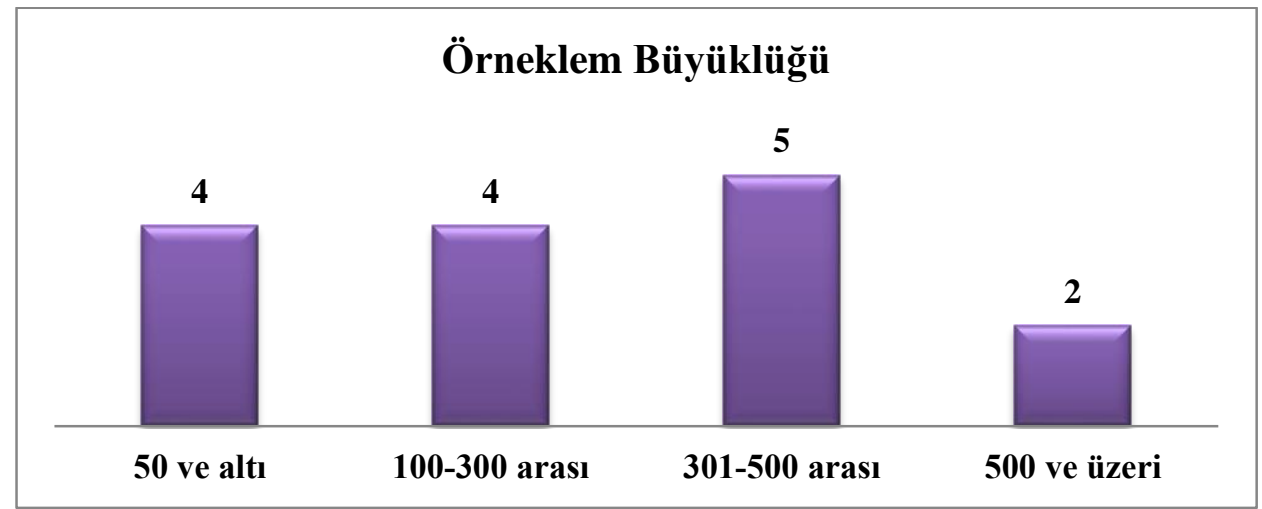

Şekil 5 Uygulamaya Yönelik Yapılmış Çalışmaların Örneklem Sayıları

Örneklem sayıları incelendiğinde en fazla 301-500 arası örnekleme sahip çalışmaların yapıldığı görülmektedir.

\section{SONUÇ VE ÖNERİLER}

Bu çalışmada savaş alanı turizmine yönelik 1997-2015 yılları arasında yapılan makaleler incelenmiştir. Yapılan yazın incelemesine göre, çalışmalar da memnuniyet, motivasyon ve ziyaret nedeni konusunun daha araştırıldığı görülmüştür. Daha sonra ise savaş alanı (hüzün) turizmi uygulamaları ve pazarlama, tanıtım ve paket tur oluşturma konusunun incelenmiştir. Mabetleştirme süreci ve savaş turizminde barışın önemi konuları da araştırmacıların ilgisini çeken konulardandır. Çalışmaların Türkiye, ABD, Avustralya ve Fransa gibi ülkelerde daha çok yapıldığı tespit edilmiştir. Yıllara göre çalışma sayıları incelendiğinde, 2005 yılından sonra çalışma sayısında bir artış olduğu görülmüştür. Özellikle 2011 ve 2014 yıllarında savaş alanı turizmiyle ilgili çalışmalar daha sık yapılmıştır.

Bu çalışma derleme özelliği gösterip mevcut yazındaki ilgili araştırmaların bir sentezi olarak hazırlanmıştır. Bundan sonra yapılacak araştırmalarda, araştırmacılara yol göstereceğine, turizm 


\section{Ozan ÇATIR}

sektöründe yer alan işletmelere de savaş alanı turizmiyle ilgili önemli katkılar sağlayabileceğine inanılmaktadır. Bu alana ilgi duyacak araştırmacılara yönelik öneriler ise;

- Türkiye'de gerçekleştirilen çalışmalarda memnuniyet, motivasyon ve ziyaret nedeni, pazarlama, tanıtım ve paket tur oluşturma ve mabetleştirme süreci konularında çalışmaların yoğunlaştığı görülmüştür. Savaş alanı turizminde barışın önemi, film endüstrisini etkisi, yöre halkına etkisi, ekonomik anlamda talep analizi, savaş alanı turizmine yönelik uygulamalar konuların da araştırmacıların çalışmalar yapması önerilmektedir.

- Türkiye'de bulunan savaş alanları turizm bölgelerinin hem ulusal hem de uluslararası alanda kıyaslamalı olarak incelenmesi gerekmektedir.

- Türkiye'de yapılan çalışmaların genellikle Gelibolu Tarihi Milli Parkı üzerine odaklandığı tespit edilmiştir. Ülkemizde bulunan diğer savaş alanları turizm bölgelerinde de çalışmaların yapılması önerilmektedir.

- Yapılan çalışmalarda savaş alanı turizminin ekonomik katkılarına yönelik çalışmalara rastlanılamamıştır. Bu yüzden özellikle yerel yönetimlerin savaş alanı turizminin yöre halkına katkıları veya olumsuz etkileri araştırılması gerekmektedir.

$\mathrm{Bu}$ alana ilgi duyacak yerel yönetimler, turizm işletme yöneticilerine yönelik öneriler ise,

- Yapılan çalışmalarda savaş alanı turizmini turistlerin yaygın olarak tercih ettiği görülmüştür. Bu bakımdan Türkiye' deki turizm çeşitliliğinin arttırılması açısından savaş alanı turizmini yerel yönetimler, seyahat acenteleri ve otel işletmeleri yöneticilerinin önemsemesi gerekmektedir.

- Savaş alanı turizm bölgelerinin çevresinin düzenlenmesinde savaşın özendirilmesi veya kötü anıların tekrardan canlandırılması yerine, barışın özendirilmesine yönelik düzenlemelerin yapılması önerilmektedir.

- Seyahat acentelerinin savaş alanlarına düzenledikleri turlarda çalıştırdıkları turist rehberlerinin bu görevi yapabilecek eğitime, donanıma, bilgiye sahip olması gerekmektedir.

- Hüzün turizmiyle ilgili savaş alanlarının dışında hüzün turizmi uygulamalarının da (film etkisi, seri katiller, ünlü mezarlıkları ziyareti vb.) Türkiye'de de uygulanabilmesinin yerel yönetimler ve turizm işletme yöneticileri tarafından uygulanması önerilmektedir.

\section{KAYNAKÇA}

Adams, C. P. (2005). Footprints in The Mud: The British Army's Approach to The Battlefield Tour Experience. Defence Studies, 5(1):15-26.

Ağaoğlu, Y. S. (2012). Visiting Gallipoli Peninsula: Perception of Australian and New Zealand Visitors Towards Anzac Day in Turkey. Gümüşhane Üniversitesi, Sosyal Bilimler Elektronik Dergisi, 6:212-218.

Alaeddinoğlu, F. ve Aliağaoğlu, A. (2007). Savaş Alanları Turizmine Tipik Bir Örnek: Büyük Taarruz ve Başkomutan Tarihi Milli Parkı. Anatolia: Turizm Araştırmaları Dergisi, 18(2):215-225.

Alexandra, D. Alexandru, C. and Larisa, T. (2014). Dark Tourism, Romania and Dracula. The Perceptions of Potential American Tourists. Annals of the University of Oradea, Economic Science Series, 23(1):309-319.

Atay, L. ve Yeşildağ, B. (2010). Savaş Alanları ve Turizm. Aksaray Üniversitesi İ̈BF Dergisi, 2(2):6772. 
Blom, T. (2000). Morbid Tourism - A Postmodern Market Niche with an Example from Althorp. Norsk Geografisk Tidsskrift- Norwegian Journal of Geography, 54:29-36.

Brian, A. Poria, Y. and Oren, G. (2011). Sought Experiences at (Dark) Heritage Sites. Annals of Tourism Research, 38(3):820-841.

Clarke, P. and Eastgate, A. (2011). Cultural Capital, Life Course Perspectives and Western Front Battlefield Tours. Journal of Tourism and Cultural Change, 9(1):31-44.

Clarke, R. Dutton, J. and Johnston, A. (2014). Shadow Zones: Dark Travel and Postcolonial Cultures. Postcolonial Studies, 17(3):221-235.

Coats, A. and Ferguson, S. (2013). Rubbernecking or Rejuvenation: Post Earthquake Perceptions and The Implications for Business Practice in A Dark Tourism Context. Journal of Research for Consumers, 23:32-65.

Cooper, M. (2006). The Pacific War Battlefields: Tourist Attractions or War Memorials? International Journal of Tourism Research, 8:213-222.

Daugbjerg, M. (2011). Not Mentioning the Nation: Banalities and Boundaries at A Danish War Heritage Site. History and Anthropology, 22(2):243-259.

Dunkley, R. Morgan, N. and Westwood, S. (2011). Visiting The Trenches: Exploring Meanings and Motivations in Battlefield Tourism. Tourism Management, 32:860-868.

Engström, C. and Boluk K. A. (2012). The Battlefield of the Mountain: Exploring The Conflict of Tourism Development On the Three Peaks in Idre, Sweden. Tourism Planning \& Development, 9(4):411-427.

Floyd, M. F. Jang, H. and Noe, F. P. (1997). The Relationship Between Environmental Concern and Acceptability of Environmental Impacts Among Visitors to Two U.S. National Park Settings. Journal of Environmental Management, 51:391-412.

Foley, M. and Lennon, J. J. (1996). JKF and Dark Tourism: A Fascination with Assassination. International Journal of Heritage Studies, 2:198-211.

Gatewood, J. B. and Cameron, C. M. (2004). Battlefield Pilgrims at Gettysburg National Military Park. Ethnology, 43(3):193-216.

Gentry, G. W. (2007). Walking with The Dead the Place of Ghost Walk Tourism in Savannah, Georgia. Southeastren Geographer, 47(2):222-238.

Gibson, D. C. (2006). The Relationship Between Serial Murder and The American Tourism Industry. Journal of Travel \& Tourism Marketing, 20(1):45-60.

Hall, J. Basarin, V. J. and Binney, L. L. (2010). An Empirical Analysis of Attendance at A Commemorative Event: Anzac Day at Gallipoli. International Journal of Hospitality Management, 29:245-253.

Hanink, D. M. and Stutts, M. (2002). Spatial Demand for National Battlefields Parks. Annals of Tourism Research, 29(5):707-719.

Herborn P. J. and Hutchinson, F. P. (2014). 'Landscapes of Remembrance' And Sites of Conscience: Exploring Ways of Learning Beyond Militarising 'Maps' of The Future. Journal of Peace Education, 11(2):131-149.

Holguin, S. (2005). National Spain Invites You: Battlefield Tourism During the Spanish Civil War. American Historical Review, 110(5):1399-1426. 
Hughes, R. (2008). Dutiful Tourism: Encountering The Cambodian Genocide. Asia Pacific Viewpoint, 49(3):318-330.

Hyde, K. F. and Harman, S. (2011). Motives for A Secular Pilgrimage to The Gallipoli Battlefields. Tourism Management, 32:1343-1351.

Iles, J. (2006). Recalling The Ghosts of War: Performing Tourism On the Battlefields of the Western Front. Text and Performance Quarterly, 26(2):162-180.

Iles, J. (2008) Encounters in The Fields - Tourism to The Battlefields of the Western Front. Journal of Tourism and Cultural Change, 6(2):138-154.

Kılıç, B. ve Akyurt, H. (2011). Destinasyon İmajı Oluşturmada Hüzün Turizmi: Afyonkarahisar ve Başkomutan Tarihi Milli Park1. Gaziantep Üniversitesi Sosyal Bilimler Dergisi, 10(1):209-232.

Kılıç, B. Kurnaz, H. A. ve Sop, S. A. (2011). Çekici Faktörlerin Destinasyon Seçimine Etkisinin Belirlenmesi ve Hüzün Turizmi İlişkisi. 12. Ulusal Turizm Kongresi Bildiri Kitabı, 30 Kasım- 4 Aralık, Düzce, 362-370.

Knox, D. (2006). The Sacralised Landscapes of Glencoe: From Massacre to Mass Tourism, And Back Again. International Journal of Tourism Research, 8:185-197.

Kurnaz, H. A. Çeken, H. ve Kılıç, B. (2013). Hüzün Turizmi Katılımcılarının Seyahat Motivasyonlarının Belirlenmesi. İşletme Araştırmaları Dergisi, 5(2):57-73.

Le, D. T. and Pearce, D. G. (2011). Segmenting Visitors to Battlefield Sites: International Visitors to The Former Demilitarized Zone in Vietnam. Journal of Travel \& Tourism Marketing, 28(4):451463.

Levitt, L. (2010). Death On Display: Reifying Stardom Through Hollywood's Dark Tourism. The Velvet Light Trap, (65):62-70.

Liu, H. H. (2012). Regeneration of Kinmen Military Installations Through the Integration of Renewable Energy Technologies and Battlefield Resources. Renewable Energy, 43:165-171.

Lunn, K. (2007). War Memorialisation and Public Heritage in Southeast Asia: Some Case Studies and Comparative Reflections. International Journal of Heritage Studies, 13(1):81-95.

MacCarthy, M. and Willson G. (2015). The Business of D-Day: An Exploratory Study of Consumer Behaviour. International Journal of Heritage Studies, 21(7):698-715.

McKay, J. (2013). A Critique of the Militarisation of Australian History and Culture Thesis: The Case of Anzac Battlefield Tourism. Journal of Multidisciplinary International Studies, 10(1):1-25.

Melstrom, R. T. (2014). Valuing Historic Battlefields: An Application of the Travel Cost Method to Three American Civil War Battlefields. J Cult Econ, 38:223-236.

Miles, S. (2014). Battlefield Sites as Dark Tourism Attractions: An Analysis of Experience, Journal of Heritage Tourism. 9(2):134-147.

Pieris, A. (2014). Southern Invasions: Post-War Tourism in Sri Lanka. Postcolonial Studies, 17(3): 266-285.

Ravi, S. (2014). Home and The 'Failed' City in Postcolonial Narratives of 'Dark Return'. Postcolonial Studies, 17(3):296-306.

Robb, E. M. (2009). Violence and Recreation: Vacationing in The Realm of Dark Tourism. Anthropology and Humanism, 34(1):51-60. 
Rofe, M. W. (2012). Considering The Limits of Rural Place Making Opportunities: Rural Dystopias and Dark Tourism. Landscape Research, 3(2):262-272.

Seaton, A. V. (1999). War and Then a Tourism: Waterloo 1815-1914. Annals of Tourism Research, 26(1):130-158.

Volcic, Z. Erjavec K. and Peak M. (2014). Branding Post-War Sarajevo. Journalism Studies, 15(6):726-742.

Walby, K. and Piche, J. (2011). The Polysemy of Punishment Memorialization: Dark Tourism and Ontario's Penal History Museums. Punishment E Society, 13(4):451-472.

West, B. (2008). Enchanting Pasts: The Role of International Civil Religious Pilgrimage in Reimagining National Collective Memory. Sociological Theory, 26(3):258-270.

Winter, C. (2009). Tourism, Social Memory and The Great War. Annals of Tourism Research, 36(4):607-626.

Winter, C. (2011a). Battlefield Visitor Motivations: Explorations in The Great War Town of Leper, Belgium. International Journal of Tourism Research,13:164-176.

Winter, C. (2011b). First World War Cemeteries: Insights from Visitor Books. Tourism Geographies: An International Journal of Tourism Space, Place and Environment, 13(3):462-479.

Yeşildağ, B. ve Atay, L. (2011). Savaş Alanları Turizmi: Gelibolu Yarımadasına Gelen Ziyaretçilere Yönelik Bir Çalışma. Balıkesir Üniversitesi, Sosyal Bilimler Enstitüsü Dergisi, 14(26):267-280.

Yırık, Ş. ve Seyitoğlu, F. (2015). Hüzün Turizmi ve Mabetleşme Süreci Kapsamında "Sarıkamış". 15. Ulusal Turizm Kongresi Bildiri Kitabı, Ankara, 1-13.

Zhang, J. J. (2010). Of Kaoliang, Bullets and Knives: Local Entrepreneurs and The Battlefield Tourism Enterprise in Kinmen (Quemoy), Taiwan. Tourism Geographies: An International Journal of Tourism Space, Place and Environment, 12(3):395-411. 